\title{
A resolução 510/16: diretrizes éticas para pesquisas em Ciências Humanas e Sociais
}

Discutir aspectos éticos envolvidos nas pesquisas em ciências humanas e sociais (CHS) é uma proposta complexa. Primeiro, porque há inúmeras comunidades científicas, cada qual com seus referenciais teóricos e metodológicos, incluídas nessa ampla denominação "CHS". Segundo, porque muitas são as maneiras de definir e aplicar, na prática, a "ética". Esse desafio é de tal grandeza que as questôes éticas vêm sendo discutidas entre pesquisadores dessas áreas há muito tempo e o tema permanece em pauta, seja de maneira específica, seja incluído nas discussóes metodológicas. Passar dessa diversidade e complexidade para a elaboração de diretrizes éticas para as pesquisas em Ciências Humanas e Sociais foi, sem sombra de dúvida, muita ousadia. Neste editorial, apresento aos leitores dos Cadernos de Terapia Ocupacional da UFSCar, a Resoluçáo 510, de 7 de abril de 2016, aprovada pelo Conselho Nacional de Saúde, que trata dos aspectos éticos das pesquisas CHS, o seu processo de elaboração, bem como de alguns de seus avanços e desafios.

A existência das resoluçóes do Conselho Nacional de Saúde (CNS) sobre ética em pesquisa e a consolidação do sistema formado por mais de 700 comitês de ética em pesquisa (CEP), os quais trabalham sob supervisão da Comissão Nacional de Ética em Pesquisa (CONEP), são um avanço para a proteção dos direitos humanos dos participantes de pesquisa no Brasil. Entretanto, essas resoluçóes foram sendo elaboradas tendo em vista a pesquisa biomédica, mais especificamente o teste de novos medicamentos, o que implica em risco significativo para os participantes. Esse processo de elaboração das normas adotou desde o início uma concepçáo de ciência positivista, que pressupóe que um pesquisador isento fará uma investigação que é replicável e que visa conhecer o que "de fato" acontece. Isso implica na crença de que o objeto em estudo náo é alterado pela presença do pesquisador e, por isso, se os procedimentos da pesquisa forem repetidos por outro pesquisador, este também chegará aos mesmos resultados. Esse contexto, no qual o compromisso do pesquisador é exclusivamente com a produçáo científica e os seus interlocutores são apenas sua comunidade acadêmica, coloca a possibilidade de tratamento inadequado do participante da pesquisa. Foi a partir dessa lógica que foram realizados os experimentos nazistas, que tanto sofrimento e morte causaram. Nessa situação, ficou evidente a possibilidade de se conduzir uma pesquisa cientificamente correta - numa perspectiva positivista - e eticamente inadequada, o que motivou a elaboração das primeiras diretrizes éticas para pesquisas com seres humanos, tais como o Código de Nuremberg, a Declaração de Helsinki, os documentos elaborados pelo Council for International Organizations of Medical Sciences (CIOMS), entre outros. A Resolução 196/96, que esteve vigente no País por mais de 15 anos, até ser revogada pela Resoluçáo 466/12 (BRASIL, 2012), informava, no seu preâmbulo, que estes foram os documentos consultados para a sua elaboração. A Resolução 466/12 manteve a mesma inspiração. Esses documentos internacionais e as resoluçôes brasileiras trouxeram avanços importantes na proteção dos direitos humanos dos participantes das pesquisas biomédicas.

Porém, quando se trata das pesquisas em CHS, que trabalham com outra concepção de ciência, a aplicação dos procedimentos descritos nessas resoluçóes pode representar retrocessos. É o caso das pesquisas nas quais os pesquisadores assumem sua presença no campo e têm a proposta de conduzir uma pesquisa cujos resultados possam trazer benefícios para os participantes, para sua comunidade e/ou para populaçôes semelhantes. Esses pesquisadores assumem, portanto, que têm interesses claros, não sendo neutros, e seus resultados dependem da relação que é estabelecida entre eles próprios e os participantes das pesquisas. Nessa situação, a qualidade da relação que se pretende estabelecer com os participantes é muito diferente da prevista nos testes de novos medicamentos e as questóes éticas envolvidas são também de outra ordem. A inadequação da Resoluçáo 196/96 para revisáo ética das pesquisas em CHS tornou-se tão evidente (GUERRIERO; DALLARI, 2008) que a Resolução 466/12 (BRASIL, 2012) afirma a necessidade de uma resolução que atenda às especificaçôes das pesquisas em CHS. Essa foi a primeira conquista que resultou de inúmeras manifestações de membros das CHS na CONEP, pesquisadores e instituições da área das CHS. 
Diante disso, a CONEP organizou o Grupo de Trabalho em Ciências Humanas e Sociais (GT CHS), cuja missão foi elaborar a minuta da resolução que trata das especificidades das pesquisas CHS.

O GT CHS/CONEP foi composto por 18 associaçôes das CHS, representantes do Departamento de Ciência e Tecnologia (DECIT/SCTIE/MS) e membros do CNS (GUERRIERO, 2016). A coordenação foi realizada por um membro titular da CONEP, da área das CHS. O financiamento do DECIT/SCTIE/MS possibilitou a realização das mais de 30 reuniôes, em Brasília. Esse GT trabalhou de agosto de 2013 a março de 2016.

O trabalho teve início com a consulta a diversos documentos nacionais e internacionais sobre ética nas pesquisas em CHS. Entre os documentos brasileiros, merece destaque o Relatório do Guarujá (SÃO PAULO, 2007), que foi o primeiro documento brasileiro elaborado com a participação de associações das CHS a oferecer sugestôes para a elaboração de uma resolução específica para CHS. No âmbito internacional, o Tri-Council Policie Statment (CANADIAN..., 2014), que estabelece as diretrizes sobre ética nas pesquisas e inclui um capítulo específico para Pesquisa Qualitativa, foi uma das referências importantes. Também foram consultados os documentos do Economic and Social Research Council (2010), além de American Psychological Association (2010), American Antropological Association (1998), Universal declaration of ethical principles for psychologists (INTERNATIONAL..., 2008) e the New Brunswick Declaration (SIMON..., 2013), entre outros. Somam-se a estes, os inúmeros artigos e publicaçóes sobre o tema.

O processo de trabalho desse GT foi intenso. "A elaboração de normas para a revisão ética de pesquisas envolvendo seres humanos é um processo político, caracterizado por disputas epistemológicas e pela luta de poder, por estabelecer uma definição de ciência” (GUERRIERO, 2015, p. S94). A disputa que havia entre as biomédicas e as CHS, durante esse GT, se atualiza entre os pesquisadores das CHS, que trabalham em diferentes paradigmas, adotam referenciais teóricos próprios e trabalham com metodologia específica. As discussôes incluíam desde a pertinência de diretrizes sobre ética em pesquisa, a necessidade (ou não) de um sistema de revisão ética, a (in)adequação de que este sistema seja sediado no Ministério da Saúde e a (in)adequação de utilizar o termo risco para as pesquisas em CHS até as diversas perspectivas para identificar quais seriam as possibilidades de dano que as pesquisas em CHS colocam aos participantes pesquisados. Embora a intenção fosse buscar o consenso, nos momentos de conclusão da minuta, houve pontos que foram decididos por votação dos membros do GT CHS.

O processo de elaboração da Minuta $\mathrm{CHS}$ incluiu várias etapas para permitir a ampla participação de todos: sistema CEP/CONEP, pesquisadores, participantes de pesquisa, enfim de toda a sociedade. A primeira versão da Minuta foi discutida no Encontro Nacional de CEP Extraordinário, realizado em outubro de 2014, em Atibaia-SP. Todas as sugestóes foram registradas e analisadas, o que resultou numa nova versão da Minuta, que foi extensamente discutida com a coordenação da CONEP. Nesse momento, houve um embate importante entre a visão biomédica e a defendida pelas CHS. Esse momento foi tão tenso que o GT CHS informou à presidência do CNS a inadequação de que a CONEP - que, naquele momento, era um colegiado eminentemente biomédico - tivesse o poder de veto sobre a Minuta elaborada. A mediação da presidente e de membros da mesa diretora do CNS nas reunióes realizadas entre o GT CHS e a coordenação da CONEP foi decisiva para o respeito à diversidade. Como resultado dessas reunióes, o GT CHS preparou a versão que foi colocada em Consulta à Sociedade, pelo CNS, no período de 21 de julho a 4 de setembro de 2015. A minuta recebeu 394 contribuiçóes, sendo 59 coletivas, elaboradas por pessoas e instituiçóes de diferentes disciplinas e áreas do conhecimento. Todas as sugestóes foram apreciadas pelo GT CHS, que fez as alteraçóes necessárias, o que resultou numa terceira versão da Minuta CHS. Essa versão foi apresentada no Encontro Nacional de Comitês de Ética em Pesquisa (ENCEP) realizado em 2015. Em 28 de janeiro de 2016, a CONEP encaminhou ao CNS a Minuta elaborada pelo GT CHS e um documento com sugestốes de alteração da Minuta. Desta vez, a CONEP solicitou a mediação da mesa diretora do CNS, para que o diálogo com o GT CHS fosse produtivo. Dos nove pontos apresentados pela CONEP, foi possível chegar ao consenso em sete desses, sendo que os dois restantes foram deliberados pela própria mesa diretora. Esse foi o processo de elaboração do texto da Resolução 510/16, que entrou em vigor em 24/maio/2016, data de sua publicação no Diário Oficial da União.

A aprovação da Resolução 510/16 foi uma vitória importante, pois marca o respeito a diferentes tradiçóes de pesquisa, enquanto mantém o foco na proteção dos direitos humanos dos participantes de pesquisa. Essa Resolução, no Art. 2, XVI, adota a seguinte definição: 
[...] pesquisa em ciências humanas e sociais: aquelas que se voltam para o conhecimento, compreensão das condiçôes, existência, vivência e saberes das pessoas e dos grupos, em suas relações sociais, institucionais, seus valores culturais, suas ordenações históricas e políticas e suas formas de subjetividade e comunicação, de forma direta ou indireta, incluindo as modalidades de pesquisa que envolvam intervenção (BRASIL, 2016, p. 4).

Portanto, independentemente da área de graduação do pesquisador, a pesquisa que se enquadrar nessa definição será revisada pelo sistema CEP/CONEP à luz da Resolução 510.

Uma questão em aberto, que foi polêmica no GT CHS, foi a adequação de utilizar uma resolução aprovada pelo CNS, cujo âmbito é saúde, para revisão das pesquisas em CHS realizadas em outros campos que não abordam a saúde. Várias associaçôes representadas no GT CHS/CONEP defendem que o sistema de revisão ética deve ficar no Ministério da Ciência, Tecnologia e Inovação - recentemente alterado pela fusão com outros ministérios -, que é o que abriga as questóes relativas a pesquisas em todas as áreas. Nesse sentido, as associaçóes argumentam que todas as pesquisas em CHS devem seguir as mesmas diretrizes. Por outro lado, considerando-se que, no Brasil, a elaboração de diretrizes para ética em pesquisa teve início no campo da saúde, outra possibilidade seria respeitar o âmbito de atuaçáo do CNS e trabalhar com a Resolução 510/16 no âmbito das pesquisas em CHS na saúde. Se essa for a opção brasileira, o País ficaria em situação semelhante à dos países bálticos, onde as pesquisas em psicologia, antropologia e sociologia só são avaliadas por um sistema de revisão ética se forem realizadas no campo da saúde, ou como o Laos, onde as pesquisas no campo da saúde (qualquer que seja o referencial teórico- metodológico empregado) deve passar por revisão ética ou ainda como a Índia, que tem diretrizes para CHS na saúde (ISRAEL, 2015). Nesse caso, ficaria evidente a lacuna normativa em relação à inexistência de diretrizes éticas para pesquisas CHS em outros campos. Essa é uma questáo séria e polêmica, que permanece em debate.

Um avanço importante ${ }^{1}$ foi a diferenciação, no texto da Resolução, Art.2, entre o processo de consentimento livre e esclarecido e o seu registro. Também se contemplou a possibilidade de que o registro seja de acordo com as características dos participantes e da pesquisa, não sendo necessariamente por escrito.

[...] processo de consentimento e de assentimento: processo pautado na construção de relação de confiança entre pesquisador e participante da pesquisa, em conformidade com sua cultura e continuamente aberto ao diálogo e ao questionamento, não sendo o registro de sua obtençáo necessariamente escrito (BRASIL, 2016, p. 4).

[...] registro do consentimento ou do assentimento: documento em qualquer meio, formato ou mídia, como papel, áudio, filmagem, mídia eletrônica e digital, que registra a concessão de consentimento ou de assentimento livre e esclarecido, sendo a forma de registro escolhida a partir das características individuais, sociais, linguísticas, econômicas e culturais do participante da pesquisa e em razão das abordagens metodológicas aplicadas (BRASIL, 2016, p. 4).

Uma vez que as pesquisas em CHS serão revisadas pelo Sistema CEP/CONEP, à luz da Resolução 510/16 (BRASIL, 2016), e as pesquisas biomédicas, à luz da Resolução 466/12 (BRASIL, 2012), a Plataforma Brasil terá de ser modificada, com a criação de um caminho diferenciado para cada área. A proposta é que o pesquisador, após fazer seu cadastro na Plataforma Brasil, irá iniciar a submissão do seu protocolo - aqui entendido como o conjunto de documentos que inclui o projeto de pesquisa, o modelo de Termo de Consentimento, as declaraçóes necessárias etc - informando a que área pertence o seu projeto. A partir dessa informação, abrir-se-ão telas específicas para cada área.

No mais, houve avanços importantes em relação à composição equânime da CONEP (Art. 33), o que pode resultar em um tratamento adequado das futuras revisóes da Res 510/16, uma vez que estas passam a ser subordinadas à aprovação de uma Comissão que inclua um número equitativo de membros das CHS. O mesmo ocorre em relação à composição dos CEP, que avaliam projetos CHS (Art. 26). Cresce, no País, o interesse das instituições em organizar CEP específicos para análise das pesquisas CHS, compostos por profissionais dessas áreas. A Norma Operacional 001/2013 (BRASIL, 2013, p. 4), ao tratar da composição dos CEP, estabelece que:

[...] o CEP será composto por, no mínimo, sete (7) membros, dentre eles, pelo menos, um representante de usuários, respeitando-se a proporcionalidade pelo número de membros. Pelo menos $50 \%$ dos membros deverão comprovar ter experiência em pesquisa. Poderá variar na sua composição, de acordo 
com as especificidades da instituição e dos temas de pesquisa a serem analisados. Terá, sempre, caráter multidisciplinar, não devendo haver mais que a metade dos seus membros pertencente à mesma categoria profissional, participando pessoas dos dois sexos. Poderá, ainda, contar com consultores "ad hoc", pertencentes, ou não, à instituição, com a finalidade de fornecer subsídios técnicos.

Portanto, um CEP composto por terapeutas ocupacionais, psicólogos, assistentes sociais, filósofos, sociólogos, antropólogos, advogados e jornalistas, para citar um exemplo, desde que não tenha mais de $50 \%$ da mesma categoria profissional, está de acordo com as normas atuais e terá mais conhecimento sobre as pesquisas CHS, o que possibilita uma revisão ética mais acurada, resultando na proteção dos participantes de pesquisa.

O momento é de comemoração pela aprovação da Resolução 510/16 e também de muito trabalho para colocá-la em prática!

\section{Referências}

AMERICAN ANTHROPOLOGICAL ASSOCIATION - AAA. Code of ethics. Arlington, 1998. Disponível em: $<$ http://www.aaanet.org/committees/ethics/ethicscode.pdf>. Acesso em: 13 ago 2016.

AMERICAN PSYCHOLOGICAL ASSOCIATION - APA. Ethical principles of psychologists and code of conduct. Washington, 2010. Disponível em: <http://www.apa.org/ethics/code/index.aspx>. Acesso em: 13 ago 2016.

BRASIL. Ministério da Saúde. Conselho Nacional de Saúde. Resolução no 466, de 12 de dezembro de 2012. Diário Oficial [da] República Federativa do Brasil, Brasília, DF, 12 dez. 2012. Disponível em: <http://bvsms.saude.gov.br/bvs/ saudelegis/cns/2013/res0466_12_12_2012.html>. Acesso em: 13 ago. 2016.

BRASIL. Ministério da Saúde. Conselho Nacional de Saúde. Norma Operacional no 001/2013. Brasília, 2013. p. 1-14. Disponível em: <http://conselho.saude.gov.br/web_comissoes/conep/aquivos/CNS\%20\%20Norma\%20Operacional\%20001\%20-\%20conep\%20finalizada\%2030-09.pdf>. Acesso em: 13 ago. 2016.

BRASIL. Ministério da Saúde. Conselho Nacional de Saúde. Resolução no 510, de 7 de abril de 2016. Diário Oficial [da] República Federativa do Brasil, Brasília, DF, 24 maio 2016. Seção 1. p. 44-46. Disponível em: <http://conselho. saude.gov.br/resolucoes/2016/Reso510.pdf>. Acesso em: 13 ago 2016.

CANADIAN INSTITUTES OF HEALTH RESEARCH - CIHR; NATURAL SCIENCES AND ENGINEERING RESEARCH COUNCIL OF CANADA - NSERC; SOCIAL SCIENCES AND HUMANITIES RESEARCH COUNCIL OF CANADA - SSHRC. Tri-Council Policy Statement: Ethical Conduct for Research Involving Humans. Ottawa, 2014. Disponível em: <http://www.pre.ethics.gc.ca/pdf/eng/tcps2-2014/TCPS_2_FINAL_Web. pdf>. Acesso em: 13 ago. 2016.

ECONOMIC AND SOCIAL RESEARCH COUNCIL - ESRC. Framework for research ethics. Swindon, 2010. Disponível em: <http://www.esrc.ac.uk/files/funding/guidance-for-applicants/esrc-framework-for-research-ethics-2010/>. Acesso em: 13 ago. 2016.

GUERRIERO, I. C. Z. O desafio da elaboraçấo de diretrizes éticas específicas para Ciências Sociais e Humanas no Brasil. Revista Faculdad Nacional de Salud Publica, Colombia, v. 33, p. S93-S102, 2015. Suplemento 1.

GUERRIERO, I. C. Z. Resolução nº 510, de 7 de abril de 2016 que trata das especificidades éticas das pesquisas nas ciências humanas e sociais e de outras que utilizam metodologias próprias dessas áreas. Ciência \& Saúde Coletiva, Rio de Janeiro, v. 21, n. 8, p. 2619-2630, 2016.

GUERRIERO, I. C. Z.; BOSI, M. L. M. Ética em pesquisa na dinâmica do campo científico: desafios na construçấo de diretrizes para ciências humanas e sociais. Ciência \& Saúde Coletiva, Rio de Janeiro, v. 20, n. 9, p. 2615-2624, 2015 .

GUERRIERO, I. C. Z.; DALLARI, S. G. The need for adequate ethical guidelines for qualitative health research. Ciência \& Saúde Coletiva, Rio de Janeiro, v. 13, n. 2, p. 303-311, 2008.

INTERNATIONAL UNION OF PSYCHOLOGICAL SCIENCE - IUPSYS. Universal declaration of ethical principles for psychologists. 2008. Disponível em: <http://www.iupsys.net/index.php/ethics/declaration>. Acesso em: 13 ago. 2016.

ISRAEL, M. Research ethics and integraty for social scientists. London: Sage, 2015.

LEITÃO, S.; FALCÃO, J. T. R.; MALUF, M. R. Ethical standards of scientific research involving human subjects in Brazil: perspectives concerning psychology. Psicologia: Reflexāo e Crítica, Porto Alegre, v. 28, n. 5, p. 40-48, 2015. 
SÃO PAULO. Prefeitura Municipal. Secretaria Municipal de Saúde de São Paulo. Relatório da reunião sobre Ética em Pesquisa Qualitativa em Saúde, realizada no Guarujá, de 28 a 30 de agosto de 2006. São Paulo, 2007. Disponível em: $<$ http://www.prefeitura.sp.gov.br/cidade/secretarias/upload/saude/arquivos/comiteetica/Relatorio_Etica_em_Pesquisa_Qualitativa_em_Saude.PDF>. Acesso em: 13 ago. 2016.

SIMON FRASER UNIVERSITY - SFU. The New Brunswick Declaration: a Declaration on Research Ethics, Integrity an Governance, resulting from the $1^{\text {st }}$ Ethics Rupture Summit, Fredericton, New Brunswick, Canada. Burnaby, 2013. Disponível em: <http://www.sfu.ca/ -palys/NewBrunswickDeclaration-Feb2013.pdf>. Acesso em: 13 ago. 2016.

\section{Iara Coelho Zito Guerriero ${ }^{\mathrm{a}, \mathrm{b}}$}

${ }^{a}$ Grupo de Trabalho em Ciências Humanas e Sociais - GT CHS, Comissão Nacional de Ética em Pesquisa - CONEP, Brasília, DF, Brasil.

bFaculdade de Medicina do ABC - FMABC, Santo André, SP, Brasil. e-mail: iara.guerriero1@gmail.com

\section{Notas}

${ }^{1}$ Outros avanços e desafios da Res 510/16 foram discutidos em Guerriero (2016). Para ler mais sobre o processo de trabalho e a proposta de tipificação e gradação de risco, veja Guerriero e Bosi (2015) e Leitão, Falcão e Maluf (2015). 